\title{
Cytomegalic inclusion disease of the newborn- A short review
}

\author{
Prashant Mule', Sanjeev H',*, K. Sneha ${ }^{3}$, Abhay Kumar ${ }^{4}$ \\ ${ }^{1,3,4}$ Consultant, ${ }^{2}$ Associate Professor, Dept. of Microbiology, Andaman and Nicobar Islands Institute of Medical Sciences, GB \\ Pant Hospital, Andaman and Nicobar Island, Port Blair, India
}

*Corresponding Author:

Email: drsanjeevh@gmail.com

\begin{abstract}
CMV infection is common in all populations but rarely associated with symptomatic illness in immunocompetent individuals. Immunocompromised patients are more commonly affected and it is a major cause of multi-organ dysfunction. The severity of disease depends upon degree of immunosuppression. Infection with CMV is extremely common but disease is a rare occurrence. The large majority of infections are clinically in apparent as with other Herpes virus infections, leading to prolonged latency, with occasional reactivation. Intrauterine or postnatal infections may lead to the development of clinical disease. Cytomegalic inclusion disease is seen almost exclusively in infants born to mothers developing primary CMV infection during pregnancy. Cytomegalic inclusion disease of the newborn or fetal death are common sequelae of Intrauterine CMV infections. This is associated with hepatosplenomegaly, jaundice, thrombocytopenic purpura and hemolytic anemia. The cytomegalic inclusion disease is probably the most important cause of microcephaly. Other manifestations are chorioretinitis and cerebral calcification. Survivors may show mental retardation. The diagnosis of CMV relies on demonstration of the agent (virus, viral proteins and nucleic acids) either in body fluids, and/or tissue or on serological responses in a patient with clinical findings consistent with CMV infection. Antivirals for systemic treatment of congenital and perinatal CMV infection are ganciclovir and valganciclovir. High-risk group such as patients undergoing allogenic bone marrow organ transplantation, acquired or innate immunodeficiency syndromes and premature infants are ideal candidates for prophylaxis against CMV infection. Administration of CMV immunoglobulins and screening of blood and organ donors for virus and its products are considered in prevention.
\end{abstract}

Keywords: Multi-organ dysfunction, Microcephaly, Chorioretinitis, Ganciclovir.

\section{Introduction}

Cytomegaloviruses (CMVs) formerly known as salivary gland viruses are double stranded DNA viruses belong to the family of herpesviridae and subfamily betaherpesviruses. Being 150-200 nm in size, CMV are the largest in the herpesvirus family. Cytomegaloviruses can be grown in human fibroblast cultures. Epithelial cell cultures are not susceptible though epithelial cells are affected in vivo. As the cytopathic effects of CMV are slow in appearance, cultures have to be incubated for up to 50 days. CMV virus is highly species specific that infects many animals including human's especially immunocompromised patients. ${ }^{1}$ The most characteristic feature is enlargement of infected cells and prominent intra-nuclear inclusions. Good pasture and Talbot (1921) used the term 'Cytomegalic' for cell enlargement in CMV infections. In 1956, the virus was isolated from human sources independently by Smith, Rowe and Weller. Weller proposed the name 'cytomegalovirus' for this group of viruses in 1960. Whenever hosts immunity is compromised, ${ }^{2}$ CMV undergoes periods of reactivation and periods latency as like other herpesviruses. The virus remains in the host's body indefinitely and can reactivate at any point of time depending on immune status. More than $80 \%$ of population in the developing world demonstrate CMV IgG antibodies, as infection with CMV is very common. The mode of transmission is via the trans-placental route. The chances of severe malformations (MF) and prognosis depends on gestational age of the fetus. The maternal infection can either be primary (in women who had never been infected before) or recurrent (by viral reactivation or reinfection by other viral strains). ${ }^{3}$ The frequency of severe complications are greater when the infection is primary as the chances of transmission to the fetus are higher. In the United States and Western Europe, CMV is a leading cause of congenital infection leading infectious cause of brain disease and hearing loss in children.

The apparent clinical disease develops in ten percent of infected newborns (NB). Infected newborns may suffer serious sequelae following infection and mortality rate may be as high as $30 \%$ to $90 \%{ }^{4}$.

\section{Clinical Manifestations of Congenital CMV Infection}

The clinical features of symptomatic CMV infections are jaundice, hepatosplenomegaly, microcephaly, intrauterine growth retardation (IUGR), prematurity, cerebral calcifications and chorioretinitis. ${ }^{5}$ Delayed clinical manifestations such as deafness, mental retardation that can all appear during the first two years of life in 10 to $15 \%$ of the newborns. ${ }^{6,7}$ Asymptomatic congenital CMV infection is defined as the presence of CMV in any secretions within the first 3 weeks of life, but with normal clinical, laboratory and radiological examinations and only about 7 to $10 \%$ have clinically evident disease at birth. ${ }^{8}$ The majority of infants born with congenital CMV infection are asymptomatic at birth. The classical triad on congenital CMV infection is constituted by jaundice $(62 \%)$, petechiae $(58 \%)$, and 
hepatosplenomegaly $(50 \%) .{ }^{9} \quad$ Other clinical manifestations include sensorineural hearing loss, oligohydramnios and polyhydramnios, prematurity, nonimmune hydrops, fetal ascites, hypotonia, poor feeding, lethargy, thermal instability, cerebral ventriculomegaly, "blueberry muffin" spots and, less frequently, hepatitis, pneumonia, osteitis, and intracranial hemorrhage. ${ }^{10,11}$
Approximately two-thirds of infants born with symptomatic congenital CMV infection shows intracranial calcifications. Infants with symptomatic CMV infection may be at increased risk for the presence of congenital malformations such as inguinal hernia in males, high-arched palate, hydrocephalus, clasp thumb deformity, and clubfoot. ${ }^{12,13}$

Table 1: Clinical presentation of congenital CMV infections

\begin{tabular}{|l|l|l|}
\hline \multicolumn{1}{|c|}{ General Findings } & CNS Manifestations & \multicolumn{1}{c|}{ Radiological Findings } \\
\hline Prematurity & Chorioretinitis & Pneumonia \\
\hline Jaundice & Microcephaly & $\begin{array}{l}\text { Periventricular, thalamic } \\
\text { and cortical calcifications }\end{array}$ \\
\hline IUGR & Seizures & Cortical dysplasia \\
\hline Purpura, petechiae & Hypotonia & Ventriculomegaly \\
\hline Hepatospleenomegaly & Hearing impairment & - \\
\hline Nonimmune hydrops fetalis & \multicolumn{1}{|c|}{-} & - \\
\hline Blueberry muffin spots & - & - \\
\hline
\end{tabular}

Congenital CMV infection needs to be evaluated very carefully for malformations. The average mortality for symptomatic congenital CMV infections is $7-10 \%$ but many researchers have reported mortality rate as high as $30 \%$. Non-cerebral manifestations of the infection, such as hepatic dysfunction or bleeding are common causes of death. ${ }^{14}$

\section{Predisposing factors for congenital CMV infection}

Study from Department of Pediatrics, University of Alabama, USA reported significant associations between congenital CMV infection and caring for preschool children in the year before delivery, onset of sexual activity $<2$ years before delivery, sexually transmitted diseases during pregnancy, household size $>$ 3 people, and maternal age $<25$ years were identified as independent risk factors. ${ }^{15}$ Preece et al. compared the mothers of a group of congenitally infected infants with those of the screened population of women with noninfected infants. ${ }^{16}$ The age of the mother, race and marital status were all individually strongly associated with the prevalence of congenital CMV infection. The overall rate of congenital CMV infection was 3/1000 live births, but it ranged from $25 / 1000$ for single black women under 20 years old to $1-6 / 1000$ in married or cohabiting white women over 25 years of age. A study conducted by Marianne A.B. et al in Gambia in 2007 reported the prevalence of congenital CMV among healthy neonates was much higher than previously reported in industrialized countries, and was associated with active placental malaria infection. There were no obvious clinical implications during the first year of life. $^{17}$

\section{Modes of Transmission}

Transmission of CMV occurs from person to person through body fluids, and requires close contact with contaminated secretions because the virus in not very contagious. CMV can be found in blood, urine, semen, cervical secretions, saliva, breast milk and transplanted organs, all these sites intermittently excrete viruses. ${ }^{18,19}$ CMV spreads slowly and probably requires close contact for transmission. It may spread through salivary or other secretions or by sexual contact. A special method of transmission is by blood transfusion or organ transplants. Congenitally infected infants have viruria for upto 4-5 years. They are highly infectious in early infancy. After primary infection, viral excretion is prolonged over years but also occurs with reactivation of latent infection. ${ }^{20}$ Transmission of CMV to fetuses and newborn infants occurs in one of following ways: (1) in utero by transplacental passage from hematogenous spread to the fetus during maternal viremia; (2) at birth by intrapartum passage after exposure to infected cervical and vaginal secretions; (3) postnatally by ingestion of CMV positive breast milk or infected blood transfusion. ${ }^{21-23}$ Infected breast milk is an even more efficient source of earlyacquired infection. Virus has been isolated from breast milk in a substantial proportion of seropositive women. Hayes et al. isolated virus from milk or colostrum from 17 of $63(27 \%)$ seropositive women and virus was isolated significantly more often after the first week than before. ${ }^{24}$ Stango et al. similarly reported high rates of isolation. In a population with a high sero-positivity rate, transmission through breast milk is likely to be a major source of early infection.

\section{Epidemiology}

Examining the sources of virus, identifying populations at risk and defining patients with deficits in immunity will better help us to understand the epidemiology of CMV infections. CMV can be cultured from most body fluids for extended periods following primary infection with significant amounts of infectious virus being found in urine, genital secretions (including semen), saliva, and breast milk. Congenital CMV 
infection is the most common viral infection of the human fetus. In the USA, the incidence of congenital CMV infection is 1 percent in live births. ${ }^{25}$ In the developing countries, the rate may be much higher. Up to 80 per cent of adults show CMV antibodies, indicating the high prevalence of infection. Once infected, the person carries the virus for life. In the developing world, rates of congenital infections as high as $2-3 \%$, suggesting that immunity does not prevent intrauterine infection. ${ }^{11}$ An estimated 10 percent of infected infants will have significant infections that result in long lasting CNS sequelae. Primary gestational infection with CMV results in a 35-50 percent fetal transmission rate, whereas gestational reactivation or reinfection in women with pre-conceptional immunity is associated with a fetal infection rate of between 1-3\%. Fetal infection following primary maternal infection during pregnancy results in damage three times more often than infection that follows reactivation or reinfection in women with preconceptional immunity. These data include the finding that maternal reinfections with a genetically different strain of CMV do occur at a significant rate (10-12\%) and that maternal reinfections can lead to damaging congenital infection. ${ }^{26}$ Many authors reported congenital infections following non-primary maternal infections could result in a similar incidence of long-term sequelae as observed in infants infected because of primary maternal infections during pregnancy. Naturally, acquired intrapartum or postnatal CMV infection in normal newborn infants has not been associated with severe infections and the permanent sequelae characteristic of infants infected in utero.

\section{Discussion}

Infection with CMV is common in all human populations and infrequently associated with symptomatic illness in normal hosts. In contrast, it is a major cause of multi-organ disease in immunocompromised patients, the severity of disease being related to the degree of immunosuppression. The role of latent infection in the transmission of CMVs by blood or during allograft transplantation is well accepted; however, the importance of latent versus a persistent productive infection in the maintenance of the virus in the individual and a population remains unclear. Human CMV can be found in tissue from a variety of inflammatory and neoplastic diseases, raising the possibility that this virus may directly or indirectly contribute to chronic inflammatory disease and cancer. Three groups of patients are at risk for invasive acute CMV disease: (1) newborn infants infected in utero, (2) immunocompromised allograft recipients (bone marrow and solid organ transplantations) and (3) patients with advanced AIDS with CD4 lymphocyte count less than 500 cells $/ \mathrm{mm}^{3}$. Infants infected in utero may be born with subclinical infections or may have a constellation of clinical abnormalities characteristic of what has been termed cytomegalic inclusion disease (CID) of the newborn. ${ }^{27}$ Cytomegalovirus disease is rare but infection with the virus is extremely common. As with herpes simplex the large majority of infections are in-apparent, leading to prolonged latency, with occasional reactivation. Clinical disease may be caused by either intrauterine or postnatal infections. Intrauterine infection leads to fetal death or cytomegalic inclusion disease of the newborn which is often fatal. This is a generalized infection associated with hepatosplenomegaly, jaundice, thrombocytopenic purpura and hemolytic anemia. The cytomegalic inclusion disease is probably the most important cause of microcephaly. Other manifestations include chorioretinitis and cerebral calcification resembling congenital toxoplasmosis. Survivors may show mental retardation. Cytomegalic inclusion disease is seen almost exclusively in infants born to mothers developing primary CMV infection during pregnancy. Infants of mothers who have CMV reactivation during pregnancy tend to have chronic subclinical infection. Perinatal infection may be acquired from the infected mother through genital secretions or breast milk. Clinical findings include hepatosplenomegaly, jaundice, thrombocytopenia, purpura, microcephaly, chorioretinitis and, rarely, pneumonia in approximately 10 percent of congenitally infected..$^{28,29}$ Mortality rates range from 11 to 20 percent in symptomatic infection, and up to 50 percent of long-term survivors of symptomatic infections will have deficits in perceptual and cognitive functions. ${ }^{30,31}$

A significant number of infants with asymptomatic infections are also at risk of developmental abnormalities, hearing loss being the most common. ${ }^{32-34}$ Persistent infection with prolonged viral shedding is nearly universal in infants with either symptomatic or asymptomatic congenital infection. ${ }^{35}$ Congenital CMV infections are currently the most common intrauterine infections worldwide, with a prevalence of 0.2 to $2.2 \%$. They are the primary infectious cause of malformations of the central nervous system (CNS) and the principal cause of deafness and learning difficulties in childhood and have a major social impact. ${ }^{36,37}$ A study in Finland detected a prevalence of congenital CMV infection of $4.8 \%$ among premature newborns, below 34 weeks, at a neonatal ICU, with full term NB not enrolled on the study.$^{38}$ In Milan, Italy, the observed prevalence among the general population of a neonatal ICU was $1 \% .{ }^{39} \mathrm{~A}$ study conducted by Santos et al. in Minas Gerais found a prevalence of congenital CMV infection at an ICU neonatal of $6.8 \% .{ }^{40}$ In a neonatal ICU in Japan a prevalence of $10 \%$ of congenital CMV infection was observed. Babies who tested positive were premature. In selected populations, such as newborn infants in neonatal intensive care units (NICU), this prevalence can climb even higher, primarily because critically ill newborns are likely to have the same risk factors. Several different studies associate adolescent mothers, black race, sexual activity with multiple partners, single marital status, multiparity, low socioeconomic status and 
contact with sources of CMV (at daycare, for example) with increased risk of congenital infection. ${ }^{41}$ A number of studies performed in Brazil have observed prevalence rates that vary, depending on study population, from 0.39 to $6.8 \% .^{42,43}$ Over a five-year period study of Kazimiera Gajl-Peczalska et all, from the Laboratory of Morbid Anatomy, Szpital Dzieciecy, Saska Kepa, Warsaw, Poland observed 20 cases of generalized cytomegalic inclusion disease, which amounts to $5 \%$ of all necropsies and $6.4 \%$ of necropsies in infants under 1 year of age, and all these children died between the second and the sixth month of life. The following criteria for differentiating the congenital and postnatal forms of the condition in infants are suggested. These criteria for differentiating the neonatal and postnatal form of the condition are suggested on the basis of clinical manifestations and necropsy findings.

Table 2: Differentiating features of cytomegalic inclusion disease of Congenital Neonatal and Post-neonatal Form

\begin{tabular}{|c|c|c|}
\hline $\begin{array}{c}\text { Neonatal } \\
\text { Period }\end{array}$ & Congenital Neonatal Form & Post-neonatal Form \\
\hline Age & Under 3 months & Over 3 months \\
\hline $\begin{array}{l}\text { Clinical } \\
\text { Features }\end{array}$ & $\begin{array}{l}\text { a) Characteristic severe form including } \\
\text { jaundice, hepatosplenomegaly, and } \\
\text { thrombocytopenic purpura, or first } \\
\text { manifestations connected with } \\
\text { infection observed during first } 4 \\
\text { weeks of life. } \\
\text { b) Presence of cerebral manifestations. }\end{array}$ & $\begin{array}{l}\text { a) Presence of another severe primary illness, e.g. } \\
\text { fibrocystic disease of pancreas or Werdnig-Hoffman } \\
\text { syndrome. } \\
\text { b) Lack of cerebral manifestations. }\end{array}$ \\
\hline $\begin{array}{l}\text { Necropsy } \\
\text { Findings }\end{array}$ & $\begin{array}{l}\text { a) Interstitial inflammation present in } \\
\text { several viscera, cytomegalic cells, } \\
\text { degenerating or containing } \\
\text { intranuclear as well as cytoplasmic } \\
\text { inclusion. } \\
\text { b) Salivary glands not involved or } \\
\text { involved with same intensity as other } \\
\text { glands. }\end{array}$ & $\begin{array}{l}\text { a) Lack of interstitial inflammation, cytomegalic cells } \\
\text { well preserved, containing mainly intranuclear } \\
\text { inclusions. } \\
\text { b) Most intense changes in salivary glands. }\end{array}$ \\
\hline
\end{tabular}

Adapted from Kazimiera gajl-peczalska et all, Cytomegalic Inclusion Disease* Laboratory of Morbid Anatomy, Szpital Dzieciecy, Saska Kepa, Warsaw, Poland, Arch. Dis. Childh., 1967, 42, 14.

Kazimiera gajl-peczalska et al, reported and discussed 20 cases of generalized cytomegalic inclusion disease in infants 2-6 months of age. Generalized cytomegalic inclusion disease was found in $5 \%$ of unselected necropsies from the laboratory of morbid anatomy of a Warsaw Children's Hospital. This apparently high figure is probably related to the rather detailed microscopical examination undertaken, since the cytomegalic cells in the investigated organs were most frequently single. Moreover, in 17 of the 20 cases other changes were found, which might have been the cause of death. The rapid acquisition of CMV infection in the first months of life in children of seropositive mothers, and its relative absence among infants of seronegative mothers suggests that the mother is the major source of infection. Of 253 infants screened at birth to exclude congenital CMV, and followed up threemonthly for one year, $12 \%$ had acquired infection by three months and $20 \%$ by one year. In all children the infection was subclinical. The mother's serological status and whether the infant was breast fed were the major factors determining the risk of acquiring infection ${ }^{44}$. Thirteen of the infected infants were re-examined at three years and all were still shedding virus in their urine. This demonstrates that virus shedding persists for years in those that acquire infection early. Unless CMV is detected in the urine within three weeks of birth, congenital and acquired infection cannot be distinguished, even when clinical problems suggestive of congenital infection are present.

\section{Diagnosis}

The diagnosis of CMV infection or symptomatic disease relies either on demonstration of the agent (virus, viral proteins and nucleic acids) in body fluids and tissue. Serological screening can be employed in a patient with clinical findings consistent with CMV infection. Diagnosis may be established by recovery of the virus from the urine, saliva or other body fluids by inoculating human fibroblast cultures. A simpler but less reliable technique is the demonstration of cytomegalic cells in the centrifuged deposits from urine or saliva. Antibody demonstration is useful in the diagnosis of primary infection but not in reactivation. Serological techniques in use include compliment fixation (CF) test, immunofluorescence and ELISA. Antibody detection may be necessary for screening blood or organ donors. Because of the ubiquitous nature of $\mathrm{CMV}$, it is important that a distinction be made between the detection of CMV and demonstration of $\mathrm{CMV}$ in the context of an 
infectious syndrome compatible with CMV. Multiple methods of recovering virus have been employed, including culture on permissive cells such as primary human fibroblasts and centrifugation enhanced culture followed by early antigen detection with monoclonal antibodies. This latter technique is widely used and can provide positive results within $24 \mathrm{~h}$. In contrast, conventional tube culture may require up to 4 weeks to reveal cytopathology. ${ }^{45}$ Congenital CMV infection has traditionally been diagnosed in the neonate via one of the following ways: (1) positive CMV culture of body fluids, (2) the presence of CMV specific immunoglobulin M titers in the infant's serum, or (3) demonstration of large intra-nuclear inclusions with small variable intracytoplasmic inclusions in CMV infected visceral cells. The molecular techniques like PCR are highly sensitive and specific and offer more accurate and reliable results with less turnaround time from direct clinical specimens. Molecular tests appears to be the most reliable means for diagnosing the infection in newborns. ${ }^{46}$ Neto et al. demonstrated in 2004 Guthrie test results from many regions in Brazil produced using ELISA-IgM serology for CMV from 15,873 newborns. Thirty-nine of them had IgM tests that were positive for CMV $(0.2 \%)$. These newborns and their mothers were retested and just $16(0.1 \%$ of the total $)$ had the result confirmed. ${ }^{47}$

Table 3: Diagnostic modalities for CMV in different group of patients

\begin{tabular}{|c|c|c|}
\hline $\begin{array}{l}\text { Type of } \\
\text { patient }\end{array}$ & Diagnostic modality & Remarks \\
\hline $\begin{array}{l}\text { Maternal } \\
\text { infection }\end{array}$ & $\begin{array}{l}\text { IgG seroconversion (appearance of virus- } \\
\text { specific IgG in the serum of a pregnant } \\
\text { woman who was previously seronegative) } \\
\text { Presence of anti-CMV IgM and IgG } \\
\text { antibodies Anti-CMV IgG avidity test }\end{array}$ & $\begin{array}{l}\text { Two consecutive maternal blood samples need } \\
\text { to be collected 2-3 weeks apart. IgM can be } \\
\text { detected in: reactivations or reinfections; until } \\
\text { more than one year after CMV primary } \\
\text { infection; interference due to rheumatoid } \\
\text { factor of the IgM class or cellular antigen; } \\
\text { false positive during other viral infections } \\
\text { (B19 Virus, Epstein Barr Virus, etc.). Low } \\
\text { avidity means recent maternal infection, but } \\
\text { threshold differs between virological methods. }\end{array}$ \\
\hline $\begin{array}{l}\text { Fetal } \\
\text { infection }\end{array}$ & $\begin{array}{l}\text { Amniocentesis to assess the presence of CMV } \\
\text { by PCR }\end{array}$ & $\begin{array}{l}\text { Perform the test after the } 21 \text { st week of } \\
\text { gestation and after } 5-6 \text { weeks from the } \\
\text { estimated onset of infection. Indications are: } \\
\text { woman with compatible clinical signs of } \\
\text { primary CMV infection; compatible } \\
\text { ultrasound abnormalities; serologic suspicion } \\
\text { of a recent maternal infection. }\end{array}$ \\
\hline $\begin{array}{l}\text { Neonatal } \\
\text { infection }\end{array}$ & $\begin{array}{l}\text { Culture or CMV-DNA testing by PCR in } \\
\text { urine, blood, throat and CSF. }\end{array}$ & $\begin{array}{l}\text { If infection is confirmed, classify as } \\
\text { symptomatic or asymptomatic and follow-up } \\
\text { at } 1,3,6 \text { and } 12 \text { months and annually until } \\
\text { school age in order to detect sequelae with } \\
\text { delayed onset. }\end{array}$ \\
\hline
\end{tabular}

Aadapted from Coll O, Benoist G, Yille Y, Weisman LE, Botet F, Anceschi MM, Greenough A, Gibbs RS, CarbonellEstrany X, Wapm; Perinatal infections working group. Guidelines on CMV congenital infections. J Perinat med 2009; 37: 433-445.

Early diagnosis of CMV infection reduces morbidity and mortality provides a scope for early therapeutic interventions. Determining the risk of future complications in asymptomatic newborns possess great challenge. ${ }^{48}$

\section{Treatment}

Ganciclovir and valganciclovir, which is an oral prodrug of ganciclovir, are commonly used for systemic treatment of congenital and perinatal CMV infection. Cidofovir and Fomivirsen are two additional drugs licensed for treatment of CMV infections in AIDS patients especially CMV retinitis. In a randomized controlled, multicenter, phase III study with ganciclovir
$(6 \mathrm{mg} / \mathrm{kg} /$ dose intravenously every 12 hour for a 6 week course) was carried out to treat newborn infants who have congenital CMV infection involving the CNS, as defined by microcephaly, intracranial calcification, abnormal findings of cerebrospinal fluid, chorioretinitis and/ or hearing deficit ${ }^{49}$. When tested at 6 months, $84 \%$ of treated infants maintained normal hearing or improved their hearing, in contrast to 59\% of control infants. At 6 months follow-up, none of the treated infants had hearing deterioration, while $41 \%$ of control patients did. Pharmacokinetic and pharmacodynamic study of oral valgancyclovir in treatment of infants with congenital CMV infection, it showed that a $6 \mathrm{mg} / \mathrm{kg}$ intravenous ganciclovir dose and $16 \mathrm{mg} / \mathrm{kg}$ oral 
valganciclovir provides similar systemic exposure to ganciclovir. Toxicity of valganciclovir is similar to that of ganciclovir with $38 \%$ of subject's developing neutropenia. A six weeks treatment with ganciclovir for symptomatic infants with congenital CMV infection involving the CNS may be considered but cannot be recommended routinely.

Table 4: Treatment of congenital CMV infection

\begin{tabular}{|l|l|l|l|}
\hline Antiviral Agents & \multicolumn{1}{|c|}{ Dosage/Duration } & \multicolumn{1}{c|}{ Blood Parameters } & \multicolumn{1}{c|}{ Remarks } \\
\hline Ganciclovir & $\begin{array}{l}6 \mathrm{mg} / \mathrm{kg} \text { twice daily, } \\
\text { intravenous, per 6 } \\
\text { weeks. }\end{array}$ & $\begin{array}{l}\text { Total Leucocyte Count (TLC), } \\
\text { renal and liver function tests, } \\
\text { blood electrolytes estimation }\end{array}$ & $\begin{array}{l}\text { Stop treatment if absolute } \\
\text { neutrophil count }<500 \mathrm{cells}^{\prime} / \mathrm{mm}^{3} \\
\text { or platelet count }<25000 \mathrm{cells} \\
/ \mathrm{mm}^{3}\end{array}$ \\
\hline Valganciclovir & $\begin{array}{l}15 \mathrm{mg} / \mathrm{kg} \text { twice daily, } \\
\text { per OS, per 6 weeks. }\end{array}$ & $\begin{array}{l}\text { Total Leucocyte Count (TLC), } \\
\text { renal and liver function tests, } \\
\text { blood electrolytes estimation }\end{array}$ & $\begin{array}{l}\text { Stop treatment if absolute } \\
\text { neutrophil count }<500 \mathrm{cells}^{2} / \mathrm{mm}^{3} \\
\text { or platelet count }<25000 \mathrm{cells} \\
\mathrm{mm}^{3}\end{array}$ \\
\hline
\end{tabular}

Source- Gandhi RS, Fernandez-Alvarez JR, Rabe H. Management of congenital cytomegalovirus infection: an evidence-based approach. Acta Paediatrica 2010; 99: 509-515.

\section{Prevention}

High-risk cases such as patients undergoing organ transplantation, immune deficients and premature infants are ideal subjects for CMV prophylaxis. Screening of blood and organ donors for CMV virus and its products is a routine clinical practice and use of CMV immunoglobulins are advocated in prevention. Acyclovir is a useful prophylactic drug but not useful in treatment. No effective vaccines are available so far. Live attenuated vaccines such as Towne 125 and AD 169 strains and a purified CMV polypeptide vaccines are under clinical trial and have been found to be immunogenic but not effective in protecting immunocompromised individuals from CMV infection. Horizontal transmission of CMV requires direct contact with infected materials that contain the virus. Adherence to standard precautions with good hand hygiene is effective to prevent $\mathrm{CMV}$ infection. ${ }^{50}$ Preexisting maternal immunity to CMV affords significant protection to the fetus. The overall risk for delivering a symptomatic neonate is about $5 \%$ with primary maternal CMV infection. ${ }^{51}$ Women of childbearing age should have CMV serological tests as routine screening procedure for any congenital infections including TORCH group of organisms. Health care professionals should provide care for young children who are potential CMV excreters and pregnant women who are CMV seronegative with information on prevention measures. ${ }^{52}$ Although newborn hearing screening programs may miss the late-onset hearing loss complicated in congenital CMV infection, routine screening of all newborns for CMV is not yet recommended. ${ }^{53}$

Funding: No funding sources.

Conflict of interest: None declared.

\section{References}

1. Weller TH. The cytomegaloviruses: ubiquitous agents with protean clinical manifestations. $N$ Engl J Med 1971;285:203-14.
2. Casteels A, Naessens A, Gordts F, De Catte L, Bougatef A, Foulon W. Neonatal screening for congenital cytomegalovirus infections. J Perinat Med 1999;27:11621.

3. Stagno S, Pass RF, Cloud GA, Britt WJ, Henderson RE, Walton PD, et al. Primary cytomegalovirus infection: incidence, transmission to the fetus, and clinical outcome. JAMA 1986;256:1904-8.

4. Berenberg W, Nankervis G. Long-term follow-up of cytomegalic inclusion disease of infancy. Pediatr 1970;37:403.

5. Pass RF, Stagno S, Myers GJ, Alford CA. Outcome of symptomatic congenital cytomegalovirus infection: results of long-term longitudinal follow-up. Pediatr 1980;66:758-62.

6. Reynolds DW, Stagno S, Stubbs KG, Dahle AJ, Livingston MM, Saxon SS, et al. Inapparent congenital cytomegalovirus infection with elevated cord IgM levels: Causal relationship with auditory and mental deficiency. N Engl J Med 1974;290:291-6.

7. Stagno S, Reynolds DW, Amos CS, Dahle AJ, McCollister FP, Mohindra I, et al. Auditory and visual defects resulting from symptomatic and subclinical congenital cytomegaloviral and toxoplasma infections. Pediatr 1977;59:669-78.

8. Conboy TJ, Pass RF, Stagno S, Alford CA, Myers GJ, Britt WJ, Mccollister FP, Summers MN, Mcfarland CE, Boll TJ. Early clinical manifestations and intellectual outcome in children with symptomatic congenital cytomegalovirus infection. J Peds 1987;111:343-48.

9. Lagasse N, Dhooge I, Govaert P. Congenital CMV infection and hearing loss. Acta Otorhinolaryngol Belg 2000;54:431-36.

10. Schimmel MS, Fisher D, Schlesinger Y. congenital cytomegalovirus infection. J Perinatol 2001;21:209-10.

11. Yamamoto AY, Mussi-pinhata MM, Cristina P, Pinto G, Moraes figueiredo LT, Jorge SM. congenital cytomegalovirus infection in preterm and full-term newborn infants from a population with a high seroprevalence rate. Pediatr Infect Dis J 2001;20:188-92.

12. Fraser SH, O'keefe RJ, Scurry JP, Watkins AM, Drew JH, Chow CW. Hydrocephalus ex vacuo and clasp thumb deformity due to congenital cytomegalovirus infection. $J$ Paediatr Child Health 1994;30:450-52.

13. Leung AK, Sauve RS, Davies HD. Congenital cytomegalovirus infection. $J$ Natl Med Assoc 2003;95:213-18. 
14. James SH, Kimberlin DW, Whitley RJ. Antiviral therapy for herpesvirus central nervous system infections: neonatal herpes simplex virus infection, herpes simplex encephalitis, and congenital cytomegalovirus infection. Antiviral Res 2009;83:207-13.

15. Fowler $\mathrm{KB}^{1}$, Pass RF. Risk factors for congenital cytomegalovirus infection in the offspring of young women: exposure to young children and recent onset of sexual activity. Pediatr 2006;118(2):e286-92. Epub 2006 Jul 17.

16. Preece, P. M., Tookey, P., Ades, A. \& Peckham, C. S. (1986). Congenital cytomegalovirus infection: predisposing maternal factors. J Epidemiol Community Health 40,205-9.

17. Marianne A.B. van der Sande, Steve Kaye, David J.C. Miles, Pauline Waight, David J. Jeffries, etall. Risk Factors for and Clinical Outcome of Congenital Cytomegalovirus Infection in a Peri-Urban West-African Birth Cohort. PubMed. 2007 Jun 6. doi: 10.1371/ PMCID: PMC1876257.

18. Stagno S, Britt W. Cytomegalovirus infections. In: Remington JS, Klein JO, Wilson CB, Baker CJ, editors. Infectious diseases of the fetus and newborn infant. 6th ed. Philadelphia: Saunders, 2006:739-81.

19. AAP committee on infectious diseases. Cytomegalovirus infection. In: Pickering LK, Baker CJ, Kimberlin DW, Long SS, editors. Red book. 28th ed. IL: Am Acad Pediatr 2009:275-80.

20. Undin MH, Gonik B. Perinatal infections. In: Martin RJ, Fanaroff AA, Walsh MC, editors. Neonatal-perinatal medicine. 8th ed. St Louis: Mosby, 2006:840-82.

21. Hamprecht K, Maschmann J, Vochem M, Dietz K, Speer $\mathrm{CP}$, Jahn G. Epidemiology of transmission of cytomegalovirus from mother to preterm infant by breastfeeding. Lancet 2001:357:513-8.

22. Revello MG, Gerna G. Pathogenesis and prenatal diagnosis of human cytomegalovirus infection. J Clin Virol 2004;29:71-83.

23. Stehel EK, Sánchez PJ. Cytomegalovirus Infection in the Fetus and Neonate. NeoReviews 2005; 6:e38-e45.

24. Hayes, K., Danks, D. M., Gila, S. H. \& Jack, I. (1972). Cytomegalovirus in human milk. N Engl J Med 1STI, 177-8.

25. Britt, W.J. and Alford, C.A. 1996. Cytomegalovirus. In: Fields, B.N., Knipe, D.M. and Howley, P.M. (eds), Fields virology. New York: Raven Press, 2493-523.

26. Ahlfors, K., Ivarsson, S.A., et al. 1999. Report on a longterm study of maternal and congenital cytomegalovirus infection in Sweden. Review of prospective studies available in the literature. Scand J Infect Dis 31, 443-57.

27. Jesionek, A. and Kiolemenoglou, B. 1904. Uber einen befund von protozoenartigen gebilden in den organen eines heriditarluetischen fotus. Munch Med Wochenschr 51, 1905-7.

28. McCracken, G.J., Shinefield, H.R., et al. 1969. Congenital cytomegalic inclusion disease. A longitudinal study of 20 patients. Am J Dis Child 117, 522-39.

29. Boppana, S.B., Pass, R.F., et al. 1992. Symptomatic congenital cytomegalovirus infection: neonatal morbidity and mortality. Pediatr Infect Dis $J, 11,93-9$.

30. Alford, C.A. 1984. Chronic intrauterine and perinatal infections. In: Galasso, G.J., Merigan, T.C. and Buchanan, R.A. (eds), Antiviral agents and viral diseases of man, 2nd edn. New York: Raven Press, 433-86.

31. Boppana, S.B., Fowler, K.B., et al. 1999. Symptomatic congenital cytomegalovirus infection in infants born to mothers with preexisting immunity to cytomegalovirus. Pediatr 104,55-60.
32. Fowler, K.B., McCollister, F.P., et al. 1997. Progressive and fluctuating sensorineural hearing loss in children with asymptomatic congenital cytomegalovirus infection. $J$ Pediatr 130,624-30.

33. Yow, M.D., Williamson, D.W., et al. 1988. Epidemiologic characteristics of cytomegalovirus infection in mothers and their infants. Am J Obstet Gynecol 158,1189-95.

34. Fowler, K.B., Stagno, S., et al. 1992. The outcome of congenital cytomegalovirus infection in relation to maternal antibody status. $N$ Engl J Med 326, 663-7.

35. Stagno, S., Reynolds, D.W., et al. 1975. Comparative serial virologic and serologic studies of symptomatic and subclinical congenitally and natally acquired cytomegalovirus infections. J Infect Dis 132,568-77.

36. Conboy T, Pass RF, Stagno S, Alford CA, Myers GJ, Britt WJ, et al. Early clinical manifestations and intellectual outcome in children with symptomatic congenital cytomegalovirus infection. $J$ Pediatr 1987;111:343-8.

37. Stagno S, Pass RF, Dworski ME, Alford CA. Congenital and perinatal cytomegalovirus infections. Semin Perinatol 1983; 7:31-42.

38. Read SJ, Jeffery KJ, Bangham CR. Aseptic meningitis and encephalitis: the role of PCR in the diagnostic laboratory. J Clin Microbiol 1977;35:691-6.

39. Panhani S, Heinonen K. Screening for congenital cytomegalovirus infection among preterm infants born before the 34th gestational week in Finland. Scand J Infect Dis 1994;26:375-8.

40. Santos DV, Souza MM, Gonçalves, SH, Cotta AC, Melo LA, Andrade GM, et al. Congenital cytomegalovirus infection in a neonatal intensive care unit in brazil evaluated by pcr and association with perinatal aspects. Rev Inst Med Trop Sao Paulo 2000;42:129-32.

41. Murph JR, Souza LE, Dawson JD, Benson P, Petheram SJ, Pfab D, et al. Epidemiology of congenital cytomegalovirus infection: maternal risk factors and molecular analysis of cytomegalovirus strains. Am J Epidemiol 1998;147:940-7.

42. Yamamoto AY, Figueiredo LT, MussiPinhata MM. Prevalência e aspectos clínicos da infecção congênita por citomegalovírus. J Pediatr (Rio J) 1999;75:23-8.

43. Panutti CS, Vilas-Boas LS, Angelo MJ, Carvalho RP, Segre CM. Congenital cytomegalovirus infection. Occurrence in two socioeconomically distinct populations of a developing country. Rev Inst Med Trop Sao Paulo 1985; 27:105-7.

44. Peckham, C. S., Johnson, C. Ades, A., Pearl, K. \& Chin, K. S. (1987a). The early acquisition of cytomegalovirus infection. Arch Dis Childhood 62,780-85.

45. Revello, M.G. and Gerna, G. 2002. Diagnosis and management of human cytomegalovirus infection in the mother, fetus, and newborn infant. Clin Microbiol Rev $15,680-715$.

46. Numazaki K, Fujikawa T. Chronological changes of incidence and prognosis of children with asymptomatic congenital cytomegalovirus infection in Sapporo, Japan. BMC Infect Dis 2004;4:22 doi: 10.1186/1471-2334-4-22 http:// www.biomedcentral.com/1471-2334/4/22.

47. Neto EC, Rubin R, Schulte J, Giugliani R. Newborn screening for congenital infectious disease. Emerg Infect Dis 2004;10:1069-73.

48. Demmler GJ. Infectious Diseases Society of America and Centers for Disease Control. Summary of a workshop on surveillance for congenital cytomegalovirus disease. Rev Infect Dis 1991;13:315-29. 
49. Kimberlin DW, Lin CY, Sánchez PJ, Demmler GJ, Dankner W, Shelton M, et al. Effect of ganciclovir therapy on hearing in symptomatic congenital cytomegalovirus disease involving the central nervous system: a randomized, controlled trial. J Pediatr 2003; $143: 16-25$

50. Demmler-Harrison GJ. Cytomegalovirus. In: Feigin RD, Cherry JD, Demmler-Harrison GJ, Kaplan SL, editors. Textbook of pediatric infectious diseases. 6th ed. Philadelphia: Saunders, 2009:2022-43.

51. Baley JE, Toltzis P. Perinatal viral infections. In: Martin RJ, Fanaroff AA, Walsh MC, editors. Neonatal-perinatal medicine. 8th ed. St Louis: Mosby, 2006:429-53.

52. Adler SP, Finney JW, Manganello AM, Best AM.

Prevention of child-to-mother transmission of cytomegalovirus among pregnant women. J Pediatr 2004;145:485-91.

53. Demmler GJ. Screening for congenital cytomegalovirus infection: a tapestry of controversies. J Pediatr 2005;146:162-4

How to cite the article: Mule P, H. Sanjeev, Sneha K., Kumar A. Cytomegalic inclusion disease of the newbornA short review. IP Int $J$ Med Paediatr Oncol 2018;4(3):85-92. 